\title{
EXPLORANDO OPERAÇÕES DISCURSIVAS NA LEITURA DE UM ARTIGO CIENTÍFICO DO CAMPO DA EDUCAÇÃO MATEMÁTICA: CONTRIBUTOS PARA A REFLEXÃO SOBBRE PRODUÇÃO DE CONHECIMENTO
}

\author{
EXPLORING DISCURSIVE OPERATIONS IN THE READING \\ OF A SCIENTIFIC ARTICLE IN THE FIELD OF \\ MATHEMATICAL EDUCATION: CONTRIBUTIONS TO A \\ REFLECTION ON KNOWLEDGE PRODUCTION
}

Thiago Mena*

\begin{abstract}
RESUMO: Neste trabalho, proponho-me a estudar o funcionamento de algumas operações discursivas presentes em um artigo científico do campo da Educação Matemática, de modo a viabilizar uma leitura crítica do conhecimento ali apresentado. Para tanto, mobilizo categorias de análise provenientes de três vertentes teóricas distintas: a Semântica Linguística, com as noções de posto, pressuposto e subentendido, estudadas por Oswald Ducrot; a Linguística Textual, com as noções de referenciação e avaliatividade, abordadas por Paulo Roberto Gonçalves Segundo; e a Metaforologia, com as noções de Metáfora Situada e Conceptual, trabalhadas por George Lakoff, Mark Johnson e Solange C. Vereza. O artigo analisado foi destacado de um corpus produzido na pesquisa que realizo no âmbito do programa de Doutorado em Educação da Faculdade de Educação da USP. Tal artigo, intitulado "Qual é o tempo médio das aulas de Matemática nas escolas públicas de periferia?", foi publicado em 2004 nos anais do "II Seminário Internacional de Pesquisa e Estudos Qualitativos: a pesquisa em debate". A análise dos dados permitiu explicitar como certos enunciados são construídos de modo a provocar efeitos de sentido que encobrem contradições, concepções equivocadas e posicionamentos autoritários no tocante ao controle da dialogicidade do texto, além de veicular determinada acepção de Educação enviesada por conteúdos positivistas e idealistas. Tais resultados evidenciam que os estudos discursivos podem contribuir para o avanço das produções científicas materializadas em textos acadêmicos do campo da Educação Matemática.
\end{abstract}

Palavras-chave: Análise de discurso; Operações discursivas; Constituição de sentidos; Artigos científicos; Educação matemática.

ABSTRACT: In this work, I propose to study the functioning of some discursive operations present in a scientific article in the field of Mathematics Education, in order to enable a critical reading of the knowledge presented there. Therefore, I mobilize categories of analysis from three different theoretical perspectives: Linguistic Semantics, with the notions of rank, presupposition and implied, studied by Oswald Ducrot; Textual

\footnotetext{
* Doutorando em Educação pela Universidade de São Paulo (USP). Professor de Matemática da rede pública municipal de São Paulo. E-mail: genio_thi@hotmail.com
} 
Linguistics, with the notions of referencing and evaluativeness, addressed by Paulo Roberto Gonçalves Segundo; and Metaphorology, with the notions of Situated and Conceptual Metaphor, developed by George Lakoff, Mark Johnson and Solange C. Vereza. The article analyzed was highlighted from a corpus produced in the research that I carry out within the scope of the Doctoral Program in Education at the Faculty of Education at USP. This article, entitled "What is the average time of Mathematics classes in public schools on the periphery?", was published in 2004 in the annals of the "II International Seminar on Research and Qualitative Studies: research in debate". Data analysis made it possible to explain how certain statements are constructed in such a way as to provoke meaning effects that cover up contradictions, misconceptions and authoritarian positions regarding the control of dialogicity in the text, in addition to conveying a certain meaning of Education biased by positivist and idealist contents. These results show that discursive studies can contribute to the advancement of scientific production materialized in academic texts in the field of Mathematics Education.

Keywords: Speech analysis; Discursive operations; Constitution of meanings; Scientific articles; Mathematics education.

\section{INTRODUÇÃO}

Este artigo foi desenvolvido no âmbito do Projeto de Pesquisa intitulado "Leitura e escrita no Brasil, Honduras, Angola e Chile: formação na universidade contemporânea e (re)produção de conhecimento" (LEBHAC), fomentado pelo Conselho Nacional de Desenvolvimento Científico e Tecnológico (CNPq). Tal projeto teve por objetivo analisar a leitura e a escrita acadêmica de alunos de diferentes áreas, inseridos em contextos culturais diversos, com vistas a verificar traços definidores dessas produções e problematizar a universidade contemporânea, tanto como espaço de formação e produção de sujeito produtor de conhecimento, quanto, consequentemente, como espaço de produção de conhecimento.

Dos objetivos específicos do Projeto LEBHAC, três deles são contemplados neste artigo, a saber: descrever as operações discursivas realizadas nas produções escritas pesquisadas; analisar o tipo de relação que $o$ aluno de pós-graduação estabelece com a palavra alheia nas suas produções escritas; e identificar e analisar (em termos de recursos linguísticos e discursivos) o que é necessário para que um texto acadêmico seja considerado uma produção que expressa um conhecimento da parte de quem o produziu. 
Neste trabalho, proponho-me a estudar o funcionamento de algumas operações discursivas presentes em um artigo científico do campo ${ }^{1}$ da Educação Matemática. Mais precisamente, mobilizo diferentes categorias de análise discursiva na leitura de um único artigo desse campo, de modo a explicitar possíveis fragilidades relativas à produção textual e ao exercício científico (considerando a intrínseca relação entre ambos os processos). Com isso, pretendo verificar as potencialidades das categorias utilizadas para o alcance de uma apreensão mais crítica tanto do conhecimento apresentado no artigo em questão, quanto do próprio processo de produção desse conhecimento.

Quanto às referidas categorias de análise, optei por recorrer a três vertentes teóricas distintas. Primeiro, a Semântica Linguística, com as noções de posto, pressuposto e subentendido, estudadas por Ducrot (1987), para discutir certas tensões que se estabelecem entre o título, os objetivos e a parte prática do trabalho. Segundo, a Linguística Textual, com as noções de referenciação e avaliatividade, abordadas por Gonçalves Segundo (2011), para estudar questões relacionadas à dialogicidade do texto, quer dizer, a forma como os autores lidam com as possibilidades de questionamento das premissas que sustentam seus argumentos. Terceiro, a Metaforologia, com as noções de Metáfora Situada e Conceptual, trabalhadas por Lakoff e Johnson (1980) e Vereza (2010), para problematizar a forma como os sentidos de Educação são constituídos no texto. Uma apresentação mais detalhada dessas categorias será feita de modo parcial, junto às análises desenvolvidas em cada seção.

Devo ressaltar que não abordo, neste texto, questões relativas às (im)possibilidades de diálogo entre as vertentes teóricas mobilizadas. Embora entenda que essa seria uma iniciativa muito promissora, tal abordagem extrapolaria os objetivos desta pesquisa, conduzindo-me a um outro enfoque investigativo. Vale dizer que a minha intenção principal aqui foi apontar, para os pesquisadores da Educação Matemática, possíveis potencialidades de algumas categorias de análise discursiva, visando a contribuir com o avanço das

\footnotetext{
1 Dado que a Educação Matemática ainda não é reconhecida pela CAPES como uma área do conhecimento, embora exista hoje uma ampla comunidade de pesquisadores que se dedicam ao estudo das múltiplas relações entre educação e matemática, optei, neste trabalho, pelo emprego do termo "campo" em vez de "área".
} 
produções acadêmicas desenvolvidas nesse campo. No fundo, foi uma modesta tentativa de aproximação entre dois campos científicos - algo que, apesar de recente, já tem sido pensado por um número significativo de autores, tais como Sartori e Duarte (2017), Alencar (2018) e Souza e Oliveira (2019). Considero que, à medida que tal aproximação for se consolidando, maiores serão as nossas (dos pesquisadores da Educação Matemática) possibilidades de participação nas discussões a respeito de questões epistemológicas relativas à área da Análise do Discurso.

O artigo escolhido como objeto deste estudo foi destacado de um corpus produzido na pesquisa que realizo no âmbito do programa de Doutorado em Educação da Faculdade de Educação da USP. Na pesquisa, analiso a constituição dos sentidos dos termos "mudança", "transformação" e "emancipação" nos discursos ancorados em textos científicos do campo da Educação Matemática, a fim de explicitar e discutir as bases ideológicas nas quais eles se sustentam. Para a produção daquele corpus, fiz um amplo levantamento dos locais onde os artigos elaborados por pesquisadores da Educação Matemática poderiam estar armazenados. Com isso, tive acesso a uma infinidade de textos, que abordavam temáticas pertinentes tanto à minha pesquisa, quanto à minha prática docente - o que me fez dedicar um tempo $\mathrm{e}$ uma atenção consideráveis às leituras.

No decorrer desse percurso, pude notar, nos textos lidos, uma possível recorrência de determinadas operações discursivas que me provocavam certo estranhamento - tais como o emprego dos termos "naturalmente" e "evidentemente" de um modo um tanto indiscriminado, ou a prática da generalização precipitada da realidade das escolas públicas com base em experiências particulares e em representações compartilhadas no nível do senso comum. Embora isso fugisse dos objetivos de minha pesquisa de doutorado, considerei importante, em algum momento futuro, lançar um olhar investigativo sobre tais percepções, para que elas não ficassem apenas no plano da 
subjetividade. Eis o que me proponho a fazer neste trabalho. Resta explicitar que o artigo aqui analisado foi escolhido por aglutinar uma série desses "pontos de estranhamento", envolvendo a produção textual, o manejo discursivo e o próprio exercício científico.

O artigo em questão foi publicado nos anais do "Il Seminário Internacional de Pesquisa e Estudos Qualitativos: a pesquisa em debate", promovido pela Sociedade de Estudos e Pesquisa Qualitativos (SE\&PQ) e pela Universidade do Sagrado Coração (USC), na cidade de Bauru, São Paulo, no ano de 2004. Seu título é "Qual é o tempo médio das aulas de Matemática nas escolas públicas de periferia?'. A autoria é compartilhada entre uma professora da UNIMEP² (hoje professora da UNESP), um aluno de mestrado da Faculdade de Educação da USP e duas professoras de Matemática da rede pública (à época, estudantes da UNIMEP).

Trata-se do resultado de um trabalho de pesquisa desenvolvido, no segundo semestre de 2002, em uma disciplina intitulada "Prática de Ensino e Estágio Supervisionado em Matemática I". Nessa pesquisa, os autores se propuseram a descrever [o cotidiano de uma escola pública localizada na periferia de Piracicaba] ${ }^{3}$, no período noturno. Para tanto, realizaram observações de aulas de Matemática em três turmas do Ensino Médio e entrevistas com os professores responsáveis. Vale mencionar que não há, no texto, maiores detalhamentos quanto: aos participantes; a forma como foram realizadas e registradas as observações e entrevistas; quais foram as perguntas feitas; sob que circunstâncias os professores foram abordados; e quanto tempo durou a pesquisa de campo. Aparentemente, foi considerada uma amostra de oito dias, sendo que em dois deles não houve aula.

O artigo é composto por 6 seção. Na introdução, é apresentado, muito sucintamente, o contexto em que se insere a pesquisa e alguns comentários referentes ao que os autores entendem por "aula de matemática". Na seção "Estágio e trabalho de campo", são oferecidos breves apontamentos a respeito de como foi realizada a pesquisa; é anunciada a forma como o estudo será

\footnotetext{
2 Universidade Metodista de Piracicaba.

${ }^{3}$ Os enunciados curtos, extraídos diretamente do artigo, apresentarei em itálico, delimitados por colchetes. Os maiores, apresentarei em um parágrafo à parte, com recuo diferenciado.
} 
apresentado; é resgatado o texto de algumas leis que versam sobre o tempo de aula e o número de alunos em sala; e são apresentadas duas tabelas contendo, aparentemente, resultados relativos ao número de alunos e ao tempo de aula observados durante a pesquisa de campo. Na seção "Os três cursos do Ensino Médio", são apresentados, em poucas linhas, 3 casos observados, com alguns cálculos relativos ao tempo médio das aulas e ao número médio de alunos. $\mathrm{Na}$ seção "Caracterização social do público: alunos de periferia", os autores se propõem, também de modo sucinto, a retratar a realidade vivenciada pelos estudantes pesquisados, mobilizando, para tanto, as referências de um autor que trabalha com a categoria marxiana de exército de reserva e discute a questão dos excluídos do mundo do trabalho. Na seção "O aparelho escolar", com uma ligeira referência à teoria dos Aparelhos Ideológicos de Estado desenvolvida por Althusser, e ao estudo dos signos culturais promovido por Baudrillard, é feita uma problematização da realidade da escola pública contemporânea, com críticas à política de "progressão continuada", sob o argumento de que essa escola não proporciona uma formação matemática que qualifique os estudantes para o mercado de trabalho. Nas "Considerações Finais", os autores defendem que os egressos das escolas públicas da rede estadual de São Paulo, especialmente aqueles que frequentaram o período noturno, têm a possibilidade de acessar o diploma escolar como valor de troca (um documento exigido para ocupar determinados espaços), mas não têm a possibilidade de gozar do seu valor de uso (que equivaleria ao emprego dos conhecimentos ali adquiridos, nos vestibulares o nos processos seletivos das empresas).

A sequência deste texto está dividida em quatro partes. Na primeira, discuto algumas tensões que se estabelecem entre o título do artigo, os objetivos assumidos pelos autores e a execução do trabalho de campo. Na segunda, discuto a forma como os autores abordam as questões metodológicas. $\mathrm{Na}$ terceira, trato das operações discursivas relacionadas ao controle da 
dialogicidade do texto. Na quarta, analiso a constituição dos sentidos de Educação ancorados no texto, com base no estudo das metáforas empregadas pelos autores.

\section{DAS TENSÕES ENTRE TÍTULO, OBJETIVOS E O TRABALHO DE CAMPO}

$\mathrm{Na}$ introdução do artigo, os autores comentam que realizaram uma pesquisa com o objetivo de descrever [o cotidiano de uma escola pública localizada na periferia de Piracicaba]. Cumpre notarmos que a palavra "uma" se caracteriza tanto como um artigo indefinido quanto como um numeral. No primeiro caso, poderíamos entender que eles estão se referindo a uma escola qualquer, dentre as várias existentes na periferia da cidade - algo que seria plausível, caso estivessem tratando de um evento aleatório de uma amostra aleatória significativa de escolas.

Porém, na descrição do trabalho de campo, os autores explicitam que [ 0 material coletado consiste em entrevistas com os professores da Escola Estadual de Ensino Fundamental e Médio e observações de aula]. A escolha da preposição "de" com o artigo definido "a", nessa sentença, é uma das evidências de que a pesquisa se refere ao estudo de um único caso. Outras evidências são os fatos de que tanto a tabela de resumo de dados relativos aos tempos de aula e número de alunos, quanto a descrição dos três casos apresentados na seção "Os três cursos de Ensino Médio" se referem a diferentes turmas de uma mesma escola.

Embora não tenha sido explicitado qual foi o critério utilizado para a escolha, podemos inferir que o estudo foi realizado em uma única escola dentre todas as escolas públicas localizadas na periferia de Piracicaba. Como se tratava de uma pesquisa desenvolvida no âmbito de uma disciplina denominada "Prática e Ensino e Estágio Supervisionado", é provável que os dados tenham sido obtidos em meio à própria atividade de estágio. A ausência de informações mais precisas nos leva a considerar o descarte das hipóteses de que tenham sido estudadas várias escolas, e de que os fenômenos descritos se refiram a uma escolha aleatória dentro de uma amostra aleatória significativa. 
Ocorre que o título do artigo, [Qual o tempo médio das aulas de Matemática nas escolas públicas de periferia?], conflita com o objetivo apresentado e com o trabalho de campo realizado. As opções pela contração prepositiva composta com um artigo definido, "nas", e pela preposição "de" sem o artigo definido, amplificam duas vezes o objeto de referência. O enunciado, assim construído, ativa a imagem de todas as escolas públicas de qualquer periferia. Sob essas condições, o questionamento acerca do tempo médio das aulas pressuporia a coleta de dados de, pelo menos, uma amostra significativa dessas escolas - o que, na prática, não se verifica. Ao que parece, trata-se de uma costumeira generalização da situação das escolas públicas em função de uma representação construída muito além do dado analisado.

Vale ponderar que algumas partes do artigo contemplam sim um exercício filosófico que até poderia indicar uma tentativa de generalização por indução, com nas seções "Caracterização social do público: alunos de periferia" e "O aparelho escolar". Entretanto, não há, no transcurso do texto, qualquer comentário, da parte dos autores, que ateste essa intencionalidade. Tampouco se verifica uma preocupação em resolver o impasse da generalização precipitada.

O que se pode observar, num primeiro momento, é um privilegiamento de estratégias publicitárias ou retóricas em detrimento do rigor científico. Há de se considerar que, apesar da contradição entre título e objetivo, o potencial de impacto de um enunciado abrangente como o que se refere à discussão do problema de todas as escolas de todas as periferias é bastante grande. Isso transmite a sensação de que os autores dominam informações significativamente abrangentes sobre o objeto de estudo - o que poderia ser considerada uma visão panorâmica e privilegiada. Porém, a ocorrência dessa operação discursiva talvez seja um indício de que os autores possuem a convicção de que realmente dominam essas informações, quer dizer, sentem-se autorizados a discorrer sobre a realidade de todas as escolas, ou sobre a escola como ente genérico, sem se debruçarem sobre uma investigação mais séria, sistemática e quantitativamente significativa. 
Para aprofundarmos essa discussão, convém recorrermos à teoria. Ducrot (1987), ao estudar a hipótese de uma semântica linguística, apresenta algumas categorias de análise que podem auxiliar nesse sentido. Trata-se das noções de posto, pressuposto e subentendido. Basicamente, na experiência da comunicação, o posto "é aquilo que afirmo, enquanto locutor" (p. 19). Já o subentendido "é o que deixo meu ouvinte concluir" (p. 19). Essa segunda categoria permite acrescentar alguma coisa "sem dizê-la, ao mesmo tempo em que ela é dita" (p. 19). Por fim, o pressuposto "é o que apresento como pertencendo ao domínio comum das duas personagens do diálogo, como o objeto de uma cumplicidade fundamental que liga entre si os participantes do ato de comunicação" (p. 20). Introduzindo uma ideia sob forma de pressuposto, "procedo como se meu interlocutor e eu não pudéssemos deixar de aceitá-lo" (p. 20).

Citando um trabalho anterior, de 1968, o mesmo autor apresenta um critério básico para classificar um enunciado como pressuposto: bastaria passar o enunciado sob análise para as formas negativa ou interrogativa e observar a manutenção ou não do sentido daquilo que assumia previamente como pressuposto. Nas palavras do autor: "os pressupostos de um enunciado continuam a ser afirmados pela negação deste enunciado ou por sua transformação" (DUCROT, 1987, p. 18). Ressalta-se que o mesmo não ocorre, necessariamente, com os subentendidos - o que nos possibilita diferenciá-los.

Voltemos à análise do enunciado empregado no título do artigo: [Qual o tempo médio das aulas de Matemática nas escolas públicas de periferia?]. Para além do que está posto, podemos acrescentar os fatos de que existem periferias neste mundo, que há escolas públicas nessas periferias, que nessas escolas há aulas de Matemática e que essas aulas são desenvolvidas em um determinado espaço de tempo. Esses seriam alguns dos pressupostos do enunciado sob investigação, os quais, de acordo com o critério de classificação apresentado anteriormente, mantêm-se preservados quando tomamos a frase em sua forma negativa: não estou interessado em saber o tempo médio das aulas de Matemática nas escolas públicas de periferia. 
Em relação ao conteúdo subentendido, temos que, de acordo com o enunciado do título, as aulas de Matemática, na prática, não possuem um tempo comum ou estável - uma vez que não seria razoável que um grupo de pesquisadores se dispusesse a calcular a média de uma variável que assumisse sempre o mesmo valor. Isto é, se todas as aulas tivessem 45 ou 50 minutos, como em geral está estabelecido nas legislações, não seria necessária a realização de uma pesquisa para calcular a média de tempos - posto que já a saberíamos de antemão.

Além disso, cumpre observarmos que os autores não se referem às aulas de Matemática realizadas em qualquer escola, mas nas "públicas de periferia". Pelo fato desses termos terem sido incluídos no enunciado do título, é possível subentender que existem particularidades relativas ao tempo da aula de Matemática realizada nas escolas públicas, em comparação às que não são públicas (quer dizer, as particulares); e que há distinções dignas de serem notadas entre as escolas públicas localizadas nas periferias e aquelas localizadas em regiões centrais.

Com base nas observações apresentadas acima, podemos inferir que os autores estão, no fundo, fazendo uma denúncia a respeito de que há variabilidade nos tempos da aula de Matemática das escolas públicas de periferia; e de que a existência dessa variabilidade é algo problemático. Resta, agora, investigarmos os motivos pelos quais essa variabilidade é assumida como problemática.

No decorrer do texto, é possível perceber que, no entendimento dos autores, a variação do tempo das aulas de Matemática está fortemente associada à questão da qualidade dessas aulas. Tal entendimento é evidenciado nestes excertos: [Sendo assim, o que chamamos de aula de matemática inclui antes da análise de sua "qualidade" o tempo e o público (alunos)]; e [A qualidade do tempo que sobra, depende também da quantidade de tempo que sobra].

Resumidamente: com base em observações e entrevistas realizadas em uma escola pública da periferia de Piracicaba, os autores identificaram a ocorrência de uma série de fatores que estaria comprometendo consideravelmente o tempo das aulas de Matemática do Ensino Médio no 
período noturno. Dentre esses fatores, estaria o caso de os alunos faltarem ou irem embora após o intervalo por conta de um jogo de futebol na TV, ou por ser sexta-feira e eles preferirem permanecer do lado de fora da escola. Sem contar o tempo gasto com atrasos, chamada e resolução de conflitos durante a aula. Tudo isso é apontado como problemas que estariam fazendo com que o tempo de aula tendesse a zero.

Acontece que, no artigo, não é descrita a forma como esses tempos de aula foram contabilizados. Além disso, os motivos apontados como determinantes para a evasão dos estudantes não foram levantados com base em uma investigação orientada por métodos científicos confiáveis, mas refletem a opinião dos professores entrevistados e, portanto, precisariam ser tomados como conjecturas, carentes de serem comprovadas. Isso indica que há ruídos na forma como os autores estão considerando tanto o processo de produção de conhecimento, quando o papel do método científico nesse processo.

\section{DA RELATIVIZAÇÃO DO RIGOR METODOLÓGICO}

Avançando para um próximo aspecto, tem-se que, ao discutir a metodologia, os autores declaram que apresentarão, [primeiramente, as análises dos resultados da pesquisa]. Para defender essa posição, apresentam o seguinte argumento:

[Entendemos que resultado por si só já diz muita coisa, naturalmente, há quem diga "depende do que foi considerado como método", concordamos com esta afirmação, entendemos que atrás dos resultados nós encontramos um procedimento, que muitas vezes estão cheios de aspectos importantes que foram desconsiderados ou que impõe um rigor no que concerne com os resultados. Seja de um modo ou de outro, não conseguimos falar sobre um trabalho de pesquisa sem um método. Porém, todo resultado de pesquisa está ligado, explícita ou implicitamente, com um posicionamento político, portanto se sustenta em uma ideologia. Aqui apresentaremos a nossa. Comecemos pelos resultados. $]^{4}$

Algo que podemos depreender, de pronto, desses enunciados é que, de acordo com a concepção dos autores, pode-se iniciar um artigo científico com a

\footnotetext{
${ }^{4}$ Grifos meus.
} 
discussão dos resultados. E assim se propõem a fazer. Entretanto, a despeito do emprego da expressão "comecemos por", que indica uma necessária continuidade, algo que venha depois, a discussão sobre os métodos não é retomada e aprofundada no transcurso do texto. Tem-se, portanto, outra contradição. Cumpre evidenciar os mecanismos discursivos empregados para sustentar tal incoerência.

No excerto apresentado, o emprego da conjunção adversativa "porém" provoca um efeito de contraposição a, pelo menos, duas proposições: (a) de que a escolha dos procedimentos de pesquisa pode desconsiderar aspectos importantes e (b) da impossibilidade de se falar de um trabalho de pesquisa sem um método. Contudo, os argumentos apresentados na sequência, relativos à dimensão ideológica da análise dos resultados, não é exatamente um contraponto a esses referentes. Trata-se de uma informação não ancorada, que rompe com o encadeamento lógico da construção, mas que, ao mesmo tempo, insere o enunciado numa formação discursiva bastante característica do contexto da pós-modernidade, qual seja a da militância política. Mas uma militância mais performática do que de fato interessada na construção de uma teoria politicamente engajada. Dessas condições, pode-se inferir que o efeito de sentido provocado pela adversativa, somada ao argumento da dimensão ideológica, é o de forjar a relativização injustificada da importância da metodologia em uma pesquisa. Tal relativização habilita a opção por não aprofundá-la, uma vez que [resultado por si só já diz muita coisa] - ou qualquer outra justificativa conveniente.

O discurso sobre diversidade ideológica (basicamente a "nossa" e a "deles") também parece ser evocado para criar uma atmosfera de militância em favor de uma ruptura com alguma forma (tradicional?) de divulgação dos resultados de pesquisa. Nesse sentido, estaria subjacente uma disputa entre os "de dentro" e os "de fora" do grupo. Esses últimos seriam aqueles que possivelmente criticariam um artigo científico no qual fora negligenciada a discussão sobre os métodos da pesquisa. Ideologia, nesse contexto, está sendo entendida como qualquer opinião manifesta por determinado grupo, o que é plausível, embora bastante superficial. Tal superficialidade, inclusive, é 
incoerente com as vozes teóricas que figuram no texto - particularmente as vozes de Karl Marx e Louis Althusser.

\section{DO CONTROLE DA DIALOGICIDADE DO TEXTO}

Em relação ao emprego do advérbio "naturalmente", grifado no excerto citado na sessão anterior, caberia uma breve discussão a respeito das marcas desse mesmo tipo que são distribuídas por todo o texto, em que se somam os advérbios "obviamente", "realmente", "certamente" e "claramente". Ao todo, contabilizam-se 16 ocorrências nas 7 páginas do artigo, das quais 9 (cerca de 60\%) são "naturalmente". Eis alguns exemplos: [Naturalmente estamos considerando a aula em seu sentido não burocrático.]; [Naturalmente o tempo é localizado por meio de data e horário...]; [Obviamente \{para $\}^{5}$ atribuir um conceito de bom (eficiente) ou ruim (ineficiente) é necessário fixar uma referência.]; [Naturalmente não se é aluno da rede pública no estado de São Paulo impunemente...]; [Naturalmente, o público em questão não adquire valor de uso...]; [Então, realmente, a escola pública assume um papel primordial neste contexto...].

Para analisar essas ocorrências, julgo pertinente conceitualizar a noção de marcas de negociação intersubjetiva, no âmbito da avaliatividade. De acordo com Gonçalves Segundo (2011, p. 169), tais marcas se referem aos "modos de construção linguístico-discursivos da presença subjetiva de escritores ou falantes em relação tanto às representações engendradas quanto aos atores sociais com quem interagem em dado evento discursivo". Esse autor, considerando a proposta de Martin e White (2005), apresenta, esquematicamente, os três grandes eixos em que se subdivide o conceito de avaliatividade, quais sejam: a atitude, o engajamento e a gradação.

Interessa-nos, neste momento, compreender os sistemas do engajamento, que seriam os "recursos linguísticos por meio dos quais falantes/escritores adotam um posicionamento diante das posições valorativas que são referenciadas pelo texto e em relação àqueles a que se dirigem".

\footnotetext{
${ }^{5}$ Intervenção minha.
} 
(MARTIN \& WHITE, 2005 apud GONÇALVES SEGUNDO, 2011, p. 175). O engajamento subdivide-se nas categorias da monoglossia e da heteroglossia. Conforme o mesmo autor, a primeira se dá quando uma proposição é construída de modo a criar um efeito de sentido que impeça a abertura de alternativas dialógicas - efeito de contração de poder e autoridade - em que se evidencia a pressuposição de aceitação de dadas avaliações ou fatos, marcando o máximo de comprometimento modal em relação ao enunciado.

Abrindo um parêntese: alguns exemplos de enunciados que são construídos de modo monoglóssico no artigo que estamos analisando são: [O que se supõe das aulas de matemática, seja qual for o período e seja qual for a escola de Ensino Médio deste país, é que exista um intervalo de tempo e espaço, alunos e professores.]; [A qualidade do tempo que sobra, depende também da quantidade de tempo que sobra.]; [Sobre as costas do valor de uso, o valor signo faz da força de trabalho qualificada valor de troca.]; [O título (diploma) que \{a escola\} ${ }^{6}$ produz não se converte em privilégio econômico para quem o possui.]; [O saber matemático imbuído de valor de uso, em nossa sociedade, significa vantagem para quem o articula.].

Há de se ponderar que seria praticamente impossível construir um texto comum sem lançar mão de enunciados monoglóssicos. Mas é importante ter em vista que eles expõem o autor de modo bastante categórico, por atribuir-lhe total comprometimento com o que foi enunciado. Nesses excertos, os autores procedem como se já não houvesse mais espaço (ou disposição) para a discussões sobre esses fatos. De certa forma, são assumidos como premissas: o que se supõe das aulas de matemática; do que depende a qualidade do tempo; como funcionam as relações entre valor de uso, valor signo e valor de troca; qual a finalidade (utilidade) do diploma; e o significado do saber matemático na sociedade.

Retomando: a segunda categoria, da heteroglossia, compreende os recursos "que possibilitam à voz autoral alinhar-se ou desalinhar-se, em vários graus, em ralação aos consumidores textuais visados ou ideais" (GONÇALVES SEGUNDO, 2011, p. 177). Esses recursos, por sua vez, subdividem-se entre os

\footnotetext{
${ }^{6}$ Intervenção minha.
} 
de expansão e contração dialógicas. Os primeiros se referem às "opções do sistema interpessoal concernentes ao reconhecimento e aceitação das vozes e posicionamentos dialógicos alternativos nos textos", e os segundos, "aos meios de desafiar, restringir ou rejeitar alternativas dialógicas" (p. 177). Ambos também se subdividem em outras duas categorias mais específicas.

Importa, para este estudo, conceituar especificamente uma das categorias da contração dialógica: a da declaração, que inclui "as formulações que limitam o escopo das alternativas dialógicas que podem ser desenvolvidas no curso do evento discursivo" (GONÇALVES SEGUNDO, 2011, p. 181), mas não rejeitam ou inviabilizam deliberadamente posicionamentos diversos. Os recursos de declaração podem ser caracterizados como de concordância, afirmação ou endosso. É, enfim, nessa primeira categoria que se enquadram as formas adverbiais tais como "naturalmente" e "obviamente". Conforme o mesmo autor, a concordância

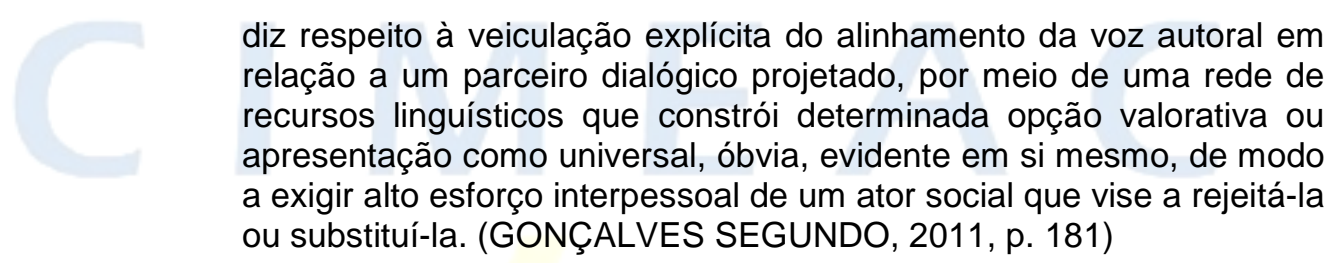

Retomemos um dos excertos citados anteriormente, ampliando agora sua região de ocorrência, para procedermos com uma análise orientada por essas categorias. $\mathrm{O}$ fragmento a seguir foi retirado do resumo do artigo.

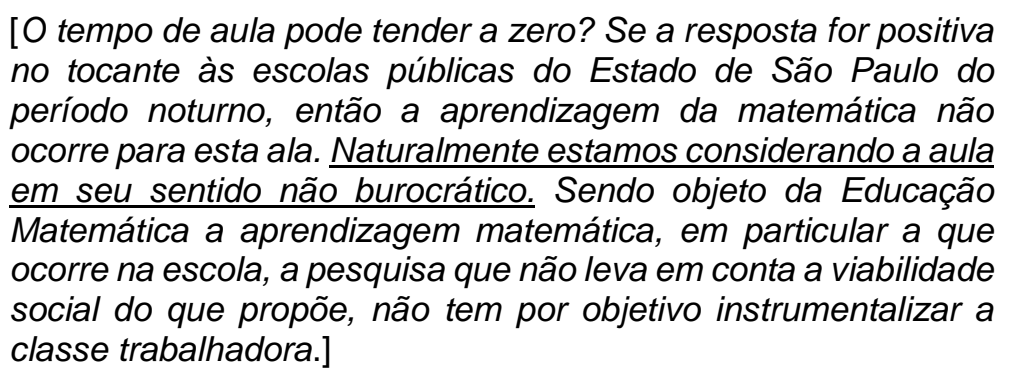

Atente que a forma adverbial de concordância "naturalmente", nesse enunciado, é uma marca de negociação intersubjetiva que contrai as possibilidades de diálogo - sem, contudo, rejeitar ou inviabilizar diretamente 
outros posicionamentos. Ela subjuga o leitor a assumir a mesma representação, quase bloqueando a alternativa segundo a qual os autores estariam sim considerando a aula em seu sentido burocrático. Com isso, provoca um efeito de sentido que atribui o valor de clareza e obviedade a um dado da pesquisa possivelmente considerado, pelos autores, como relevante ao julgamento de um ou mais interlocutores idealizados.

Além disso, o enunciado está alocado entre outros dois, cujas significações também dependem do controle dessa representação. Assim, em contraposição, haveria um "sentido burocrático da aula" que não suportaria o questionamento acerca da possibilidade de seu tempo tender a zero, e a partir do qual não se poderia pensar na viabilidade social do que nessa aula se propõe realizar. Neste ponto, outra contradição se faz evidente. Refere-se ao fato de que, apesar de afirmarem que consideram a aula em seu sentido não burocrático, os autores discutem o espaço e tempo das aulas de Matemática com base na Lei Federal 9.394/96. Afinal, não seria esse, juntamente, o seu sentido burocrático?

\section{METÁFORAS CONCEPTUAIS E OS SENTIDOS DA EDUCAÇÃO}

Ainda sobre o mesmo excerto, caberia uma breve análise dos processos metafóricos que o permeiam. O questionamento inicial, sobre a possibilidade de o tempo da aula tender a zero, mobiliza um léxico característico do campo da Matemática - área de formação dos autores - que nos reporta à teoria dos limites. Conforme Guidorizzi (2008, p. 55), "dizer que o limite de $f(x)$, quando $x$ tende a $p$, é igual a $L[\ldots]$ significa que quando $x$ tende a $p, f(x)$ tende a $L$." $A$ representação $f(x)$ se refere a uma função qualquer cuja variável seja $x$. A função estabelece a correspondência entre dois conjuntos numéricos e a variável ocupa um espaço que pode assumir qualquer valor. Assim, dependendo do valor atribuído ao $x$, a função assumirá um valor $f(x)$ correspondente. Na teoria dos limites, estuda-se o comportamento dessa função quando $0 x$ tende $a$ determinado número "p". 
Se fizermos corresponder o enunciado [O tempo de aula pode tender a zero?], no contexto do artigo, à definição de limite exposta acima, teremos algo como: a aula de Matemática é uma função $\mathrm{f}(\mathrm{x})$; o tempo é uma variável $\mathrm{x}$ da função $f(x)$; a anulação da possibilidade de ocorrência da aula de Matemática é o resultado do limite de $f(x)$ quando $x$ tende a zero. Observa-se, aqui, um caso de nicho metafórico, definido por Vereza (2013, p. 5) como "desdobramentos textuais de uma ou mais metáforas locais e episódicas". Estas últimas são também referidas como metáfora situada, a qual, conforme a mesma autora, "apesar de estruturar cognitivamente textos específicos, [...], não precisa ser explicada linguisticamente" (p.6).

No exemplo em análise, ainda que os autores não a tenham explicitado, podemos inferir a metáfora situada O PROCESSO DE ENSINOAPRENDIZAGEM DA MATEMÁTICA É UMA FUNÇÃO DA VARIÁVEL TEMPO DE AULA. Tal inferência se justifica pelo caráter estruturante dessa metáfora no conjunto do texto. Tem-se em conta que, sem ela, as demais metáforas no nicho não fruiriam o mesmo efeito de sentido. Observe este outro enunciado: [Acreditamos que qualquer um que julgue seu próprio juízo há de considerar que não há qualidade a ser comentada se o tempo de aula é de 15 minutos ou se tende a um valor menor.]. Nesse caso, o termo "qualidade" faz referência ao cumprimento satisfatório do processo de ensino-aprendizagem e a conjunção "se" sugere uma relação de dependência - no caso, do tempo de aula. Essa relação se estabelece a partir de um objeto discursivo preliminar constituído metaforicamente.

Vereza (2013, p. 6) também explica que a metáfora situada "conduz, cognitiva e discursivamente, todo um desdobramento, um mapeamento textual, online, episódico, construindo um determinado objeto de discurso (MONDADA e DUBOIS, 2003) ou um ponto de vista, de uma maneira deliberada". Se procedermos a um mapeamento do domínio fonte (teoria das funções) e do domínio alvo (processo de ensino-aprendizagem da Matemática), obtemos: 


\begin{tabular}{|c|c|}
\hline Domínio fonte & Domínio alvo \\
\hline $\begin{array}{l}\text { O resultado da função } f(x) \text { varia de acordo } \\
\text { com o valor assumido pela variável } x \text {. }\end{array}$ & $\begin{array}{l}\text { O resultado do processo de ensino- } \\
\text { aprendizagem da Matemática varia de } \\
\text { acordo com o tempo da aula. }\end{array}$ \\
\hline $\begin{array}{c}\text { A função } f(x) \text { tende a "L" quando a variável } x \\
\text { tende a "p". }\end{array}$ & $\begin{array}{l}\text { O processo de ensino-aprendizagem da } \\
\text { Matemática tende a não acontecer quando o } \\
\text { tempo da aula tende a zero. }\end{array}$ \\
\hline $\begin{array}{c}\text { Há correspondência unívoca entre um } \\
\text { elemento e o valor associado a ele pela } \\
\text { função. Ou seja, para cada valor assumido } \\
\text { pela variável independente } x \text {, há um único } \\
\text { valor da variável dependente } f(x)\end{array}$ & $\begin{array}{l}\text { Para cada valor relativo à quantidade de } \\
\text { tempo de aula corresponde um único } \\
\text { resultado no processo de ensino- } \\
\text { aprendizagem da Matemática. }\end{array}$ \\
\hline $\begin{array}{c}\text { Duas funções } f(x) \text { e } g(x) \text { são ditas iguais } \\
(f=g) \text { se, e somente se, para cada valor de } x \\
\text { no domínio, } f(x) \text { e } g(x) \text { assumem o mesmo } \\
\text { valor. }\end{array}$ & $\begin{array}{l}\text { Dois processos de ensino-aprendizagem da } \\
\text { Matemática são ditos igual se, e somente se, } \\
\text { para cada valor correspondente à } \\
\text { quantidade de tempo de aula, os dois } \\
\text { processos alcançam o mesmo resultado. }\end{array}$ \\
\hline
\end{tabular}

Percebe-se que a metáfora situada em questão possibilita a construção de um objeto de discurso perpassado por um ponto de vista particular, carregado de valores que reverberam por todo o texto. Observando a progressão do mapeamento, vão se evidenciando traços de determinismo próprios da ciência Matemática, que são projetados, mesmo inconscientemente, nos domínios da aula e do processo de ensino-aprendizagem. O campo lexical do domínio fonte denuncia esse determinismo, ao comportar termos como unívoco, igual, único e mesmo, além de expressões como "se, e somente se", "para cada", "varia de acordo com". Em vista do caráter cognitivamente estruturante dessa metáfora, o domínio alvo acaba por ser pensado também por intermédio dessas noções, fomentando as ideias de padronização e enrijecimento curricular, didático, metodológico e avaliativo.

Paralelamente à conceituação das metáforas situadas, Vereza (2010) também apresenta a noção de metáfora conceptual, forjada pelos pesquisadores ingleses George Lakoff e Mark Johnson (1980). Esse tipo de metáfora, conforme a autora, "faria parte de um 'inconsciente cognitivo coletivo', mantendo uma relação de determinação mútua com a cultura e com a língua" (VEREZA, 2010, p. 205). A metáfora conceptual teria o sentido de construção sociocognitiva do real. Trata-se de uma perspectiva cognitivista segundo a qual "as expressões metafóricas encontradas na linguagem são evidências de metáforas conceptuais que as licenciam" (VEREZA, 2010, p. 206). A autora esclarece que os estudiosos 
cognitivistas da metáfora buscam identificar, por meio de marcas linguísticas, as metáforas conceptuais que a subjazem.

Nesse sentido, se derivarmos, por relação hiperonímica, a expressão "processo de ensino-aprendizagem" para o termo Educação, e a expressão "função da variável tempo" para o termo Ciência Exata, alcançaremos uma metáfora ainda mais basilar, que poderia ser caracterizada como uma metáfora conceptual. Qual seja, A EDUCAÇÃO É UMA CIÊNCIA EXATA. A explicitação dessa metáfora ajuda a compreender a concepção de Educação que possivelmente estava em jogo no processo de separação das áreas do Ensino e da Educação da CAPES, bem como na anterior edificação do campo do Ensino de Ciências e Matemática, e mesmo na iniciativa de sustentação da autonomia do campo científico da Educação Matemática. Cumpriria agora buscar mais evidências que ajudem a sustentar essa tese, além de problematizar a ideia de Educação como uma Ciência Exata, sobretudo do ponto de vista ideológico, haja vista o caráter positivista e idealista dessa concepção.

\section{CONSIDERAÇÕES FINAIS}

De modo geral, o uso frequente das declarações de concordância "naturalmente", "obviamente", "realmente", "certamente" e "claramente", associado à recorrência de construções monoglóssicas, indica uma tendência dos autores a tentar reprimir a dialogicidade do texto, demonstrando certo autoritarismo no controle dos processos de significação. Seria, entretanto, precipitado afirmar que o texto é mais ou menos fechado ao diálogo, posto que não foram aqui analisados, qualitativa e quantitativamente, os recursos de expansão dialógica empregados - o que possibilitaria uma comparação.

Caberia avaliar que o fato de os autores trabalharem com a suposição de tantos consensos e consentimentos acaba por fragilizar o processo de recepção textual, e, consequentemente, o processo de disseminação de suas conclusões. Aproveitando o argumento de Gonçalves Segundo (2011, p. 182), a identificação potencial de qualquer ator social com alternativas dialógicas 
"constitui ameaça direta à solidariedade discursiva". Na prática, tal ameaça pode acarretar o desengajamento do consumidor textual na leitura do artigo.

Em relação à metáfora situada O PROCESSO DE ENSINOAPRENDIZAGEM DA MATEMÁTICA É UMA FUNÇÃO DA VARIÁVEL TEMPO DE AULA, valeria reclamar todas as outras variáveis que - não por acaso, mas por um posicionamento ideológico - ficaram apagadas nesse estudo. Variáveis cuja relevância provavelmente seria até maior para explicar o fracasso da instituição escolar contemporânea (particularmente as escolas públicas das periferias) no tocante à formação matemática dos filhos da classe trabalhadora. O que dizer, por exemplo, da metáfora O PROCESSO DE ENSINOAPRENDIZAGEM DA MATEMÁTICA É FUNÇÃO DAS VARIÁVEIS ALIMENTAÇÃO E MORADIA DIGNAS? Ou ainda, O PROCESSO DE ENSINOAPRENDIZAGEM DA MATEMÁTICA É FUNÇÃO DAS VARIÁVEIS COR DE PELE, GÊNERO E CLASSE SOCIAL A QUE SE PERTENCE?

\section{REFERÊNCIAS}

ALENCAR, A. C. Uma análise discursiva sobre a história da matemática presente no livro didático de matemática. Boletim Cearense de Educação e História da Matemática. V. 5, n. 14, p. 299-310, 2018.

DUCROT, O. O dizer e o dito. Revisão técnica da tradução: Eduardo Guimarães. Campinas, SP: Pontes, 1987.

GONÇALVES SEGUNDO, P. R. Tradição, dinamicidade e estabilidade nas práticas discursivas: um estudo da negociação intersubjetiva na imprensa paulistana. Tese (doutorado em Filologia e Língua Portuguesa). Faculdade de Filosofia, Letras e Ciências Humanas da Universidade de São Paulo, FFLCH/USP: São Paulo, 2011.

GUIDORIZZI, H. L. Um curso de cálculo. Volume 1, 5a ed. 6ª reimpressão. Editora LTC, Rio de Janeiro, 2008.

LAKOFF, G. e JOHNSON, M. Methaphors we live by. Chicago: University of Chicago Press, 1980.

MARTIN, J. R. e WHITE, P. R. R. The Language of Evaluation: appraisal in English. London: Palgrave/Macmillan, 2005. 
SARTORI, A. S. T.; DUARTE, C. G. O sujeito lúdico produzido pela/na Educação Matemática: interlocuções com o neoliberalismo. Bolema, Rio Claro (SP), v. 31, n. 57, p. 53-xxx, abr, 2017.

SOUZA, L. G. R.; OLIVEIRA, M. A. A matemática como discurso: uma análise da relação mulher-matemática na obra $O$ Homem que Calculava, de Malba Tahan. Bolema, Rio Claro (SP), v. 33, n. 64, p. 871-891, ago. 2019.

VEREZA, S. O lócus da metáfora: linguagem, pensamento e discurso. Caderno de Letras da UFF - Dossiê: Letras e Cognição n. 41, p. 199-212, 2010.

."Metáfora é que nem...": Cognição e discurso na metáfora situada. Signo, v. 38, n. 65, p. 02-21, 2013.

\section{CORPUS DE ANÁLISE}

MATTOS, A. C.; SILVA, A.; FAVARO, F. F.; MANDRO, P. C. B. E. Qual é o tempo médio das aulas de Matemática nas escolas públicas de periferia? Anais do II Seminário Internacional de Pesquisa e Estudos Qualitativos: a pesquisa em debate. Sociedade de Estudos e Pesquisa Qualitativos (SE\&PQ) e Universidade do Sagrado Coração (USC), Bauru, São Paulo, 2004. Disponível em: http://arquivo.sepq.org.br/llSIPEQ/Anais/pdf/gt2/10.pdf. Acesso em: 07/2018. 